\title{
LA PRESENCIA DE CALCOS ESTRUCTURALES Y SEMÁNTICOS EN TWITTER: EL CASO DEL ESPAÑOL DE CATALUÑA*
}

\section{THE PRESENCE OF STRUCTURAL AND SEMANTIC LOANWORDS IN TWITTER: THE CASE OF SPANISH IN CATALONIA}

\author{
Joseph García RodríGUez \\ Universidad Autónoma de Barcelona (UAB) \\ joseph.garcia@uab.cat
}

Enviado: 09/08/2017

Aceptado: 03/02/2018

\begin{abstract}
Resumen
En este artículo pretendemos contribuir al avance de las características propias del español de Cataluña a partir del análisis de 21 verbos y expresiones verbales que suelen presentar alguna especificidad en el uso por el contacto entre el español y el catalán. La novedad de este estudio reside, sobre todo, en los datos aportados acerca del contacto entre estas dos lenguas en una de las redes sociales más conocidas y utilizadas por los internautas: Twitter; así como su proyección en las formas verbales. A través de la información obtenida podremos describir con detenimiento la influencia que ejerce el catalán sobre el español y analizar los calcos estructurales y semánticos que aparecen. Asimismo, en la parte teórica aportamos datos que demuestran
\end{abstract}

\begin{abstract}
In this paper, our aim is to contribute to the advance of the characteristics of the Spanish in Catalonia from the analysis of 21 verbs and verbal expressions which usually present some specificity in the use that reveals the contact between Spanish and Catalan. The novelty of this study lies, above all, in the data provided about the contact between Spanish and Catalan in one of the most popular social networks easily accessible to Internet users: Twitter; as well as its projection in verb forms. Through the information obtained we can describe in detail the influence of Catalan on Spanish and analyse the structural and semantic loanwords that appear. In the theoretical part, we also provide data that show the importance of social
\end{abstract}

* Esta investigación se ha podido desarrollar gracias a la ayuda del Ministerio de Economía y Competitividad para el proyecto "El español de Cataluña en los medios de comunicación orales y escritos" (FFI2016-76118-P) y al apoyo del «Pla de l'AGAUR» de la Generalitat de Catalunya para el grupo de investigación consolidado «Grup de Lexicografia i Diacronia» (2017 SGR 1251). Con el apoyo de la Secretaria d'Universitats i Recerca del Departamento de Economía y Conocimiento de la Generalitat de Catalunya.

Para citar este artículo / To cite this article: García Rodríguez, Joseph (2018). La presencia de calcos estructurales y semánticos en Twitter: el caso del español de Cataluña. ELUA, 32: $131-154$. doi: 10.14198/ELUA2018.32.6

Enlace / Link: http://dx.doi.org/10.14198/ELUA2018.32.6 
la importancia de las redes sociales en la comunicación actual. Todo esto nos ayudará a establecer el punto de partida de nuestro análisis.

PALABRAS CLAVE: Lexicología, contacto de lenguas, Twitter, español, catalán. networks in current communication. All this will help us to establish the starting point of our analysis.

KEYWORDS: Lexicology, languages in contact, Twitter, Spanish, Catalan.

\section{INTRODUCCIÓN}

El modo en que los seres humanos establecemos nuestras relaciones ha ido evolucionando con el tiempo, ya que a lo largo de la historia han surgido nuevos canales de comunicación dirigidos a facilitar, según los medios disponibles, la interacción entre las personas. Este es el caso de algunas aplicaciones digitales de las que disponemos en la actualidad, cuya función es permitir el contacto constante entre personas mediante mensajes escritos, fotografías, vídeos e imágenes, entre otros. Las redes sociales, como Twitter, Instagram y Facebook, por citar algunas, son un claro ejemplo de ello. Tanto la cantidad de mensajes enviados y compartidos a lo largo del día como la predisposición a utilizar estos medios en detrimento de otros más tradicionales ha provocado que algunos estudiosos ya se atrevan a afirmar que existe un nuevo modelo de comunicación basado en la rapidez, la participación y la información disponible en tiempo real cuyo uso ha revolucionado la manera en que las personas interactuamos (Pérez, 2010). Los conocidos como millennials, es decir, las personas nacidas en plena revolución tecnológica entre los años 80 y 2000 junto con, obviamente, las sucesivas generaciones, son los más acostumbrados a utilizar este tipo de redes, por lo que no es de extrañar que para ellos la manera prioritaria de comunicarse sea a través de las aplicaciones existentes.

Desde el punto de vista lingüístico, todo esto conlleva nuevas perspectivas de estudio. Las redes sociales pueden ayudarnos a encontrar evidencias de usos de la lengua hasta ahora solo detectables, por ejemplo, mediante grabaciones. Aun así, es necesario señalar que "la lengua en las redes sociales es un tipo de discurso que no se puede interpretar estrictamente en términos de lengua hablada o lengua escrita" (Moreno Sandoval y Moreno Fernández, 2017: 1), sino que más bien debe entenderse como una mezcla entre ambas, puesto que se utiliza la escritura como medio para transmitir el mensaje y el modo en que este se expresa contiene características propias de la lengua oral. En este sentido, tenemos a nuestro alcance una cantidad de datos inasumibles que reflejan los usos lingüísticos más allá de lo puramente normativo. Esto puede ser interesante, por ejemplo, a la hora de observar el empleo de palabras y/o expresiones propias de una comunidad bilingüe surgidas del contacto de lenguas. El análisis de mensajes publicados por hablantes bilingües que utilizan la redes como medio de expresión habitual puede ayudarnos a conocer más en profundidad los rasgos lingüísticos propios de la zona estudiada. En esta investigación nos vamos a centrar en el contexto español-catalán y, con ello, contribuir a la descripción del español empleado en Cataluña.

\section{CONTACTO DE LENGUAS Y REDES SOCIALES: TWITTER COMO FUENTE DE INFORMACIÓN}

En una comunidad bilingüe como Cataluña, los fenómenos del contacto de lenguas, es decir, aquellas manifestaciones que surgen de la convivencia entre dos o más lenguas en 
un mismo territorio son abundantes. Tradicionalmente se ha hablado de interferencia para referirse al resultado de este contacto como consecuencia de una desviación de la norma (Weinreich, 1979 [1953]); sin embargo, no siempre ha sido aceptada esta denominación, ya que algunos autores aseguran que contiene matices peyorativos asociados normalmente a la concepción de error (Blas Arroyo, 1991). Ante tal perspectiva, Clyne (1967) prefiere usar el término transferencia para evitar esta connotación, puesto que el contacto de lenguas y los posibles fenómenos subyacentes deben considerarse como un proceso natural. Payrató (1985) expone la dificultad que supone intentar definir la denominación de interferencia lingüística debido a los múltiples sentidos que los estudiosos han ido incorporándole. Aun así, este autor concibe dicho fenómeno como parte de un cambio lingüístico (una innovación, una pérdida o una sustitución), que puede darse en una lengua determinada (o registro), y que se produce por el influjo de otra lengua (o de otro registro de la misma lengua) con la que está en contacto. En este estudio utilizaremos el término interferencia por ser el más extendido en las investigaciones que se han desarrollado sobre este tema. Asimismo, desde la perspectiva seguida en esta investigación, a dicho vocablo no se le asociarán valores negativos.

Relacionado con los conceptos anteriores, también se ha utilizado el término préstamo para indicar la transferencia de una lengua a otra de un término o una expresión (Gómez Capuz, 1998; Moreno Cabrera, 2016). En el contexto que nos atañe también suele acuñarse el vocablo catalanismo, considerado como un hipónimo de préstamo que, para esta investigación, "desde un punto de vista etimológico, designará todo aquello que "viene del catalán', sea voz patrimonial o no para esta lengua [...]” (Prat Sabater, 2003: 29). De entre los préstamos, se hará la distinción entre dos tipos de calcos, en función de si solo se ha tomado prestada la parte formal, es decir, el significante (calco estructural) o el significado del elemento (calco semántico) (Haugen, 1953; Gómez Capuz, 1998)². Otro término que se utilizará en este estudio es el de integración (Mackey, 1970), definido como la incorporación en la lengua destino (con el beneplácito de la norma) de una palabra o expresión identificada anteriormente como interferencia o préstamo. De este modo, un elemento puede llegar a convertirse en parte de la lengua receptora debido al uso, la frecuencia y la normativización.

Un ejemplo de lo expuesto anteriormente es lo que sucede con el español de las zonas catalanohablantes. La interferencia lingüística aparece cuando el español de estas zonas adquiere características del catalán que no son reconocidas como válidas por la norma, es decir, el resultado del contacto entre estas dos lenguas es un elemento agramatical. Los investigadores han estudiado este fenómeno desde un punto de vista fonético, morfológico, léxico y semántico, aunque cabe destacar que en la actualidad existen otros estudios que demuestran los cambios que se producen a nivel pragmático y discursivo (Sinner, 2004). Aun así, el uso extendido de un elemento considerado a priori como interferencia puede convertirse en un préstamo y llegar a integrarse en la lengua receptora: como ejemplo, fango o granel son préstamos aceptados del catalán que aparecen en el DLE; mientras que pescatería o pescatero no se registran. El DPD (s.v. pescadería) sí que recoge información acerca de estos vocablos:

1 Como calco se entiende cualquier elemento, en este caso, léxico o gramatical, proveniente de otra lengua, que ha sufrido un proceso de adaptación (sobre todo ortográfico) para incorporarse en la lengua meta. 
'Tienda donde se vende pescado': «En una pescadería recomendada por el dueño de La Marqueta encargó una rascasa» (VqzMontalbán Soledad [Esp. 1977]). Para designar a la persona que vende pescado se emplea el derivado pescadero. Estas son las formas pertenecientes a la norma culta del español general; en Navarra (España) y en zonas donde el español convive con el catalán se usan a veces las variantes dialectales pescatería y pescatero.

En algunas investigaciones como la de García Sanz (2011), por ejemplo, sí que se documenta el uso de estos sustantivos en los periódicos de La Vanguardia y El País, lo que nos ayuda a corroborar el empleo de estas palabras en las zonas de habla catalanas.

Asimismo, tal y como señala Blas Arroyo (2004), es posible hablar de convergencia lingüística cuando, por ejemplo, el español adquiere ciertas estructuras del catalán, pero a diferencia de la interferencia, los componentes adoptados no son agramaticales, sino que responden a un uso preferente de ciertas estructuras por influencia de alguna de las dos lenguas: haber de + infinitivo en detrimento de tener que + infinitivo en el español de Cataluña por el uso exclusivo y normativo de la primera opción en catalán. Autores como Sinner (2000) y García Sanz (2011) aseguran que la primera forma es más frecuente en el español de Cataluña en los textos escritos, a diferencia del resto de zonas hispanohablantes; sin embargo, Galindo Solé (2003) señala que los resultados obtenidos a partir de las grabaciones realizadas en contextos espontáneos no ayudan a confirmar que esto sea así, ya que los datos proporcionados por la autora demuestran cómo solo 1 de los 104 casos estudiados prefiere el uso de haber de en vez de tener que. En este sentido, Galindo Solé sugiere lo siguiente:

The data analysis does not confirm the frequency of appearance of structures that coincide with the Catalan ones. [...] the variants that are more frequent in non Catalan-speaking areas are also the habitual forms in the varieties of Castilian spoken in Catalonia (2013: 23).

Las aportaciones de todos estos autores no deben entenderse como contradictorias, ya que aún en la actualidad carecemos de estudios estadísticos exhaustivos que nos permitan conocer de primera mano la frecuencia de uso de estas y otras estructuras en el español empleado por catalanes.

Con todo, aunque la existencia de un posible español de Cataluña ha sido estudiada en algunas obras como Sinner (2004); Sinner y Wesch (2008); y Poch Olivé (2016), esta última incluye, también, investigaciones en torno al contacto del español con el gallego y el euskera; todavía es necesario seguir profundizando en sus posibles características para determinar qué elementos forman parte de dicha comunidad y cuáles pueden considerarse como interferencias no reconocidas todavía por la norma.

Para poder identificar estos fenómenos, es necesario tener en cuenta los posibles medios en que las personas interactuamos de forma natural, puesto que es una de las condiciones indispensables para conocer de primera mano los posibles casos relacionados con el contacto de lenguas. Si tenemos en cuenta que las redes sociales abarcan un número de usuarios muy elevado, llegamos a la conclusión de que este tipo de medios nos van a proporcionar una cantidad de datos lingüísticos relevantes que nos permitan analizar distintos fenómenos. Sin ir más lejos, los datos nos ayudan a reforzar el argumento expuesto anteriormente. Según el informe de la Sociedad de la Información en España (2016), en adelante SIE, unos 27,7 millones de españoles son usuarios de internet. De esta cifra, el 
$66,7 \%$ utiliza las redes sociales (un $3 \%$ más que en 2015) y, más concretamente, el 82,8 $\%$ de los catalanes se conectó a la red en los tres últimos meses previos a la publicación del informe. Con todo esto es posible advertir la importancia que ha adquirido internet, en general, y las aplicaciones, en particular, para la comunicación diaria de las personas, ya que el $90,9 \%$ de los internautas suelen utilizar estos medios para comunicarse con familiares y amigos (SIE, 2016).

Todo esto convierte a las redes sociales en fuentes inagotables de información que nos permiten observar los usos lingüísticos típicos de los hablantes, ya que los mensajes publicados están íntimamente relacionados con los registros conversacional y coloquial que suelen darse en la lengua oral (Sánchez Sánchez, 2012). En esta investigación nos centraremos en Twitter, ya que, como señalan Moreno Sandoval y Moreno Fernández (2017: 1), esta red

[...] destaca por ser una de las más difundidas internacionalmente. Este servicio de "microblogs" ofrece características reseñables desde el punto de vista lingüístico: la primera es la limitación en el número de caracteres, lo que obliga a una simplificación del contenido y a una flexibilización de la forma. Esto afecta negativamente al estilo sintáctico o discursivo, pero no al léxico. Por otra parte, la espontaneidad e inmediatez de los mensajes los sitúa muy próximos al discurso oral, en el que nacen muchos de los préstamos léxicos.

Esta aplicación fue creada en 2006 con poco éxito, pero en el año 2009 se produjo un incremento muy considerable de usuarios que empezaron a compartir información, así como a comunicarse con otras personas (Polo García, 2009). Algunas investigaciones que se han desarrollado en torno a esta aplicación han demostrado la importancia que ha adquirido para, sobre todo, la gente joven (los que anteriormente hemos denominado millennials), puesto que, según los datos aportados por la SIE (2016), prefieren enviar y recibir mensajes que realizar una llamada telefónica. Además, los usuarios pueden crearse un perfil en el que conste parte de su biografía y, así, conocer, por ejemplo, su ubicación geográfica. De este modo, es posible detectar la zona en la que reside el individuo en cuestión, lo que facilita la búsqueda de mensajes creados en Cataluña. Asimismo, tal y como añaden Mocanu, Baronchelli, Perra, Gonçalves, Zhang y Vespignani (2013), Twitter permite conocer la geolocalización de los mensajes enviados, lo cual posibilita conocer qué lenguas son las más utilizadas en un territorio determinado, así como su expansión en la red. En el caso del español y el catalán en Cataluña, estos autores aseguran que en el área de Barcelona el español y el catalán se encuentran entremezclados, a diferencia de lo que sucede en las demás zonas de esta comunidad, donde el catalán parece poseer una mayor presencia de tuits. Sin embargo, calculan que, en Twitter, las dos lenguas más usadas para expresarse entre los usuarios catalanes son el español (49 \%) y, en segundo lugar, el catalán (29,2\%). Los investigadores señalan que este recuento está de acuerdo con lo que recoge el censo, por tanto, esto demostraría la validez y la fiabilidad de los datos manejados en línea:

Going at a deeper level of inspection, we see that the Catalan language is more widely used in the central and Northern part of the region than in the area of Barcelona and the coast connecting this city to Tarragona. Remarkably, this pattern agrees with the overall picture provided by census data, thus confirming once again the validity of online data in providing meaningful informations, even at the within-country scale (Mocanu, Baronche1li, Perra, Gonçalves, Zhang y Vespignani, 2013: 4). 
Si tenemos en cuenta que en las redes sociales intervienen personas con lenguas diferentes, es posible afirmar que Twitter es una plataforma multilingüe en la que podemos encontrar mensajes publicados en distintos idiomas, observar cuáles son las lenguas predominantes y conocer el perfil de las personas que interactúan sobre un tema determinado. Ivković y Lotherington (2009: 30) aseguran que "In public spaces, including virtual space, languages coexist and form multilingual discourses, with assumed multilingual speakers acting as a cohesive element between different linguistic codes". En este sentido, debido al uso en Twitter de múltiples idiomas, incluidos los que aquí nos conciernen, la presencia de fenómenos relacionados con el contacto de lenguas será abundante, lo que nos va a permitir comprobar algunos de los datos aportados por anteriores estudios relacionados con el español de Cataluña, así como reflexionar acerca de los usos lingüísticos que los internautas emplean cuando se comunican mediante este tipo de redes.

\section{LA COMUNICACIÓN EN TWITTER}

Como se ha comentado en apartados anteriores, los mensajes escritos en Twitter no pueden considerarse pertenecientes a la oralidad, ni tampoco a la escritura. Si bien es cierto que los mensajes publicados en este medio son escritos, el carácter coloquial y conversacional que adquiere el contenido de los mismos es indiscutible. Por este motivo, es necesario diferenciar entre el medio en que se produce el mensaje y la concepción subyacente que encontramos en él. Esta distinción, propuesta por Koch y Oesterreicher (2007), tiene en cuenta no solamente el modo en que se difunde lo que pretendemos transmitir, sino también las características propias del contexto discursivo (registro e intención comunicativa, por ejemplo). Los autores señalan que la lengua oral suele estar relacionada con la inmediatez, mientras que la escritura tiende a presentar cierta distancia comunicativa. Con todo, es pertinente trazar un continuo en el que, según las características que presente el discurso en cuestión, sea posible ubicar el contenido del mismo en una zona más próxima a la oralidad o a la escritura. En el caso de Twitter, nos encontramos ante una red social que podría situarse más cercana a la inmediatez comunicativa, ya que permite compartir en tiempo real e instantáneo cualquier tipo de información, así como mantener una conversación en línea mediante el intercambio de mensajes públicos o privados. Por este motivo, algunos autores, como Lara (2011) y Mancera Rueda y Pano Alamán (2013) creen conveniente identificar las cuatro funciones comunicativas que pueden poseer los mensajes publicados en Twitter: la de reconocimiento, la dialógica, la discursiva y la identitaria. La primera de ellas hace referencia al estatus de autoridad que un usuario otorga a la información publicada por otra persona mediante el retuit; la segunda está relacionada con la posibilidad de mantener una conversación con alguien mediante el uso de algunas etiquetas precedidas por la arroba; la tercera consiste en el seguimiento de los mensajes publicados en torno a un tema concreto; y la cuarta está vinculada con la información que proporcionan los perfiles de los usuarios (fotografía y datos publicados por ellos mismos). Relacionado con las funciones comunicativas, también es posible establecer una clasificación de los tuits publicados según el contenido de los mensajes. Mancera Rueda y Pano Alamán (2014a), siguiendo las aportaciones de Shaffer, Freund y Welch publicadas en 2013, diferencian entre estos tipos de tuits: 
[...] pass along: mensaje dirigido a otro usuario con un enlace a contenidos externos; conversacional-fático: mensaje dirigido a otro usuario que no contiene contenido informativo, sino que confirma, rechaza, evalúa lo dicho por otro usuario; informativo: contiene información interna (sobre las políticas llevadas a cabo por el gobierno, por ejemplo); búsqueda de información: contiene preguntas/solicitudes de información dirigidas a los usuarios; solicitud de participación: por ejemplo, para pedir retuits; noticias: por lo general relacionadas con eventos recientes; y de estado: respuestas a la pregunta ¿Qué estás haciendo? [...] (2014a: 237-238).

En el análisis que desarrollaremos en apartados posteriores se hará referencia explícita a las funciones comunicativas y a los tipos de tuits que suelen contener algún fenómeno relacionado con el contacto de lenguas.

Desde el punto de vista lingüístico, es necesario tener en cuenta el registro al cual se adhieren la mayoría de tuits que constituyen nuestro corpus. Como se podrá comprobar a continuación, es posible señalar que la mayoría de tuits recogidos puede situarse en un registro coloquial, lo cual estaría en sintonía con las observaciones de Mancera Rueda y Pano Alamán (2014a: 240): "las interacciones que tienen lugar en Twitter se acercan en distintos grados a la conversación coloquial prototípica"2. Independientemente del canal escrito en el que se transmiten los tuits, el contenido de los mismos suele presentar rasgos marcados por la proximidad entre los interlocutores, la comunicación en tiempo real, la no planificación de los mensajes publicados, la expresión de opiniones, sentimientos y emociones, y la descripción de acciones cotidianas. Aun así, como señala Androutsopoulos (2008: 16), "the spoken/written relationship is deemed considerably more complex than just a transfer of spoken features to written texts or a not-further-specified 'hybrid' amalgamation of both". Por tanto, para poder entender el modo en que se produce la interacción en este tipo de redes sociales es necesario hablar de un discurso emergente (Mancera Rueda y Pano Alamán, 2013), en el que entran en juego nuevos modos de comunicación, como la relación entre los mensajes escritos, las imágenes y las dinámicas interactivas que se producen en este tipo de redes, cuyo marco de enunciación suele estar fijado en el presente por la inmediatez en el intercambio de mensajes e informaciones.

Los usuarios pueden utilizar la red para comunicarse libremente, lo que nos permite a los investigadores observar los usos lingüísticos surgidos de un contexto coloquial en detrimento de los aspectos puramente normativos (Thurlow y Mroczeck, 2011). Es necesario tener en cuenta, también, que el contexto en el que se enmarca la comunicación es determinante a la hora de seleccionar ciertos elementos léxicos y estructuras sintácticas, es decir, normalmente, en los tuits recopilados para el análisis de nuestro corpus, se puede observar cómo se trata de opiniones o muestras de emociones, lo que facilita la aparición de un registro coloquial.

\section{CORPUS Y FUNDAMENTOS METODOLÓGICOS DEL ESTUDIO}

La presente investigación se ha llevado a cabo con 50 verbos y expresiones verbales que, según autores como Szigetvári (1994), Sinner (2004) y Sinner y Wesch (2008), apa-

2 En este trabajo entendemos coloquial como "propio del léxico, de las expresiones o del nivel de uso que se caracteriza por la inmediatez, la escasa o nula planificación de los mensajes que se producen y la cercanía en el trato de las personas que participan en la comunicación. Suele darse en situaciones distendidas, aunque no se descarta su presencia (limitada) en otros contextos" (García Rodríguez, 2014: 4). 
recen bajo algún fenómeno relacionado con el contacto de lenguas español-catalán. Más concretamente, analizaremos los 21 verbos y expresiones verbales más frecuentes según los autores anteriormente mencionados ${ }^{3}$. En total se han obtenido más de 60 ejemplos extraídos de Twitter, de los cuales solo se mostrarán 32 para no exceder los límites de extensión establecidos. Como criterio principal, se han escogido los casos más representativos por contener información contextual relevante y así facilitar su comprensión al lector (Mancera Rueda y Pano Alamán, 2014b). También se ha tenido en cuenta el año de publicación, ya que los estudios precedentes más relevantes aportan datos anteriores al año 2010, por lo que hemos creído conveniente actualizar estas aportaciones recogiendo los mensajes posteriores a esta fecha. La extracción de los tuits que componen el corpus ha sido manual, mediante el buscador avanzado que nos proporciona Twitter. A partir de los resultados obtenidos, se han escogido aquellos mensajes más representativos, es decir, los que contienen información contextual suficiente como para poder comprender el enunciado completo. Es necesario señalar que esta investigación se centra en la provincia de Barcelona con el fin de poder describir detalladamente el uso de la lengua por parte de los hablantes de esta zona. Para ello, hemos recogido aquellas evidencias en las que aparece la información geográfica de los usuarios responsables de los mensajes publicados. Así pues, no hemos tenido en cuenta aspectos como el sexo o la edad, puesto que no son datos relevantes para los objetivos de la presente investigación. En futuros estudios sí que pretendemos incluir dichas variables sociológicas, así como analizar otras provincias, con la intención de obtener un panorama completo sobre el español de Cataluña.

Asimismo, se ha clasificado cada elemento que conforma el corpus según el fenómeno del contacto de lenguas con el que puede relacionarse, aunque solo haremos referencia a calcos estructurales y calcos semánticos por ser los más abundantes en nuestro corpus. Para complementar el análisis, se han consultado las obras normativas tanto del español ( $D L E$, 2014) como del catalán (DIEC2, 2007), así como el DPD (2005) para cuestiones relacionadas con el uso y la norma. La información de las obras prescriptivas se ha complementado con el Diccionario de dudas y dificultades de la lengua española (DDD, 1998).

Sin duda, los resultados obtenidos en esta investigación nos permitirán ahondar en las características del español de Cataluña y, más concretamente, de Barcelona, en uno de los medios de comunicación más utilizados en la actualidad.

\section{EL USO DE VERBOS Y EXPRESIONES VERBALES POR PARTE DE USUA- RIOS DE TWITTER CATALANES}

A continuación, se desarrollará un análisis esencialmente cualitativo de los datos de los que disponemos en dos apartados: en primer lugar, se estudiarán los calcos estructurales que hemos encontrado en nuestro corpus; y, en segundo lugar, se analizarán detalladamente los casos que hemos clasificado como calcos semánticos ${ }^{4}$.

3 Cada verbo y expresión analizados cuenta como un elemento del corpus, por lo que para los verbos dar y hacer deben contarse de manera independiente cada una de las estructuras estudiadas.

4 En futuras investigaciones sería interesante realizar un análisis estadístico con la metodología pertinente para observar la frecuencia de uso de estos verbos y expresiones. 


\subsection{Calcos estructurales}

Uno los vocablos que podemos encontrar en Twitter como muestra del contacto entre el español y el catalán es enchegar. Este verbo, que clasificamos como calco estructural adaptado procedente del verbo catalán engegar, se utiliza con frecuencia entre los usuarios catalanes de esta red social ${ }^{5}$ :

(1) "Mi madre es mala, me apaga la tele para que me tenga que levantar a enchegarla, ya no sabe que desde el mando se puede enchegar" (Montcada i Reixac, 02/01/2012).

(2) "Enchego la tele para ver el Barça-Madrid, y 2 goles en 2 minutos que lo veo" (Badalona, 30/07/2017).

El DIEC2 (s. v. engegar) define esta palabra como "Fer que (una cosa) comenci a anar, a funcionar, a rutllar", por lo está vinculado con el término encender, definido por el $D L E$ (s. v. encender) como "Hacer que funcione un dispositivo o un aparato eléctrico". En este sentido, en los ejemplos (1) y (2) se utiliza el verbo enchegar en detrimento de encender, para referirse a 'poner en funcionamiento'. Aunque su uso no se recoge en ninguna obra normativa del español, según la información encontrada en Twitter, algunos hablantes sí que conocen y utilizan este verbo ${ }^{6}$. De todos modos, también es posible observar cómo algunos tuiteros son conscientes de su poca aceptación en contextos formales y, por consiguiente, la falta de prestigio que posee el empleo de esta forma en determinadas situaciones; de ahí que normalmente se intente evitar su uso. Un ejemplo de esto es el siguiente tuit: "Lo he vuelto a hacer. He vuelto a decir 'enchegar' en vez de 'encender"' (Viladecans, 29/12/2013). Ante mensajes como este, es posible advertir la influencia de la norma sobre la concepción que poseen los hablantes acerca del uso de la lengua. Si bien es cierto que este vocablo suele escucharse a menudo en las zonas catalanas, su empleo fuera de estos territorios suele conllevar una reacción por parte de los interlocutores, debido, seguramente, a una cuestión de actitudes lingüísticas, donde aquello que se distancia de lo normativo, y de la variedad estándar de la lengua, suele llamar la atención a quienes participan en la conversación. Por lo que se refiere a los cambios adoptados para su incorporación al español, el verbo originario engegar cambia la grafía $g$ por el dígrafo $c h$, lo que convierte la fricativa posalveolar sonora del catalán en una africada palatal sorda en español. Autores como Sinner y Wesch (2008) lo identifican como catalanismo, aunque reconocen que pueden encontrarse evidencias de uso en otros territorios de habla hispana.

Podemos observar cómo los dos tuits anteriores son puramente informativos, puesto que explican situaciones cotidianas. Estos mensajes son una muestra del tipo de interacción que se produce en Twitter, ya que ambos usuarios comparten en tiempo real lo que están haciendo (2) o lo que les está pasando (1). La función comunicativa que aparece es la discursiva, ya que ambos tuits permiten una respuesta y un seguimiento de las publicacio-

\footnotetext{
5 Para facilitar la comprensión de los mensajes extraídos se han modificado algunos elementos que aparecen en los tuits originales (cuestiones ortográficas y abreviaturas). Asimismo, en ocasiones se ha añadido información contextual mediante corchetes para que el lector pueda entender el mensaje en su totalidad. Para mantener la privacidad, también se ha decidido mostrar los mensajes de forma anónima, aunque sí presentamos el lugar desde donde se han escrito y la fecha de publicación porque son datos pertinentes para nuestra investigación.

6 Para completar dicho análisis y aportar datos estadísticos, en próximas investigaciones se realizará un estudio sobre las frecuencias de los verbos y expresiones tratados en esta investigación.
} 
nes relacionadas con el mensaje inicial. Esto es más claro en (2), donde a posteriori otros usuarios comentan lo que están viendo en relación con el partido de fútbol. Asimismo, la inmediatez comunicativa, la cercanía de los mensajes y determinados componentes (la afirmación irónica "Mi madre es mala" y la repetición de enchegar dos veces), son algunos de los elementos que identifican estos tuits como parte del registro coloquial.

Otro ejemplo de calco estructural lo encontramos en encontrar a faltar, expresión utilizada en detrimento de echar de menos. En catalán se emplea la combinación trobar a faltar con el significado de "Adonar-se que no és allà on hauria d'ésser, sentir-ne la llunyania, la pèrdua, la desaparició" (DIEC2, s. v. faltar), lo que demuestra que la expresión utilizada por los siguientes tuiteros es una traducción literal de la misma al español, puesto que utilizan el equivalente pleno del verbo trobar (cat.) - encontrar (esp.) para construir la locución:

(3) "Hay demasiados lugares en Barcelona donde encuentro a faltar tu magia..." (Barcelona, 13/02/2016).

(4) "Pese a la opinión de muchos, yo lo voy a encontrar a faltar, para mí de los mejores que han pasado por el Barça, grande Luis Enrique" (Mataró, 27/05/2017).

Es necesario señalar que el $D L E$ (s. v. falta) también recoge la combinación echar en falta, que remite a la más frecuente: echar de menos. Si tenemos en cuenta que esta variante se parece a la expresión catalana, es posible que los hablantes tengan más dificultades para identificar el calco como un elemento resultante del contacto entre las dos lenguas. El DPD (s. v. encontrar(se) y echar(se)), además de recogerlas como catalanismos, muestra otra posible variante, cuyo uso debería evitarse, y que resulta, también, de la influencia con el catalán: echar a faltar. Asimismo, el DDD (s. v. hallar) indica que también existe otra combinación posible, como es hallar a faltar, de "uso propio del español hablado por catalanes".

Por lo que se refiere a los tipos de tuits, (3) es informativo porque la intención del usuario es comunicar lo que siente y (4) es conversacional-fático por el hecho de que el autor del mensaje expresa su opinión a partir de lo que han comentado otras personas anteriormente. En cuanto a las funciones comunicativas que desempeñan estos mensajes, podemos decir que (3) estaría relacionado con la dialógica, puesto que está dirigido a un usuario en concreto; y (4) se identificaría con la discursiva porque forma parte de una conversación en la que participan varias personas que siguen el mismo tema. También podemos encontrar rasgos coloquiales: en (3) se observa una proximidad entre el autor del mensaje y su destinatario debido, sobre todo, a la expresión de sentimientos; en (4), además de tratarse de una opinión, hallamos una expresión propia de este registro, como "grande Luis Enrique", cuya intención es alabar a la persona que va pospuesta al adjetivo.

En esta misma línea encontramos la presencia de dos estructuras verbales: estar de algo y estarse de algo (este último formulado normalmente en negación) como sustitución de acabar y abstenerse, respectivamente. Estos calcos estructurales de las formas catalanas estar, definida como "Cessar de fer quelcom" (DIEC2, s. v. estar), y estar-se de fer alguna cosa, con el significado de "Privar-se'n, no fer-la" (DIEC2, s. v. estar), pueden encontrarse en Twitter:

(5) "Ya estoy de cenar y todo, así que cuando te pongas, me avisas [...]" (Terrassa, 28/08/2012).

(6) "El Ppodrido no se está de nada: corrupción, saqueo, mentiras, y ahora hipocresía y cinismo" (Badalona, 24/11/2016). 
En (5), la usuaria le otorga el valor de 'acabar' para referirse a que ha finalizado la acción, en este caso, cenar. En español no encontramos un uso similar con el verbo estar, por lo que nos permite confirmar que se trata de un empleo basado en la influencia catalana. En cuanto al ejemplo (6), observamos que la estructura no estarse de nada para denotar 'no abstenerse de algo' es una traducción literal de la combinación catalana presentada anteriormente, puesto que la obra lexicográfica normativa del español no recoge este uso. Sin embargo, el $D D D$ (s. v. estar) señala que es un "catalanismo que a veces pasa al castellano hablado por catalanes".

Estos tuits pueden identificarse como informativo (5) y conversacional-fático/informativo (6): el primero comunica un estado en tiempo real y solicita al interlocutor que responda al tuit cuando esté disponible y el segundo expresa un juicio de valor sobre el Partido Popular (PP), aunque también informa de la situación política del momento. Como en los dos casos anteriores, (5) desempeña una función dialógica por ir dirigido a una persona en concreto; mientras que (6) estaría relacionado con la discursiva, ya que forma parte de un tema en el que participan varias personas. El registro coloquial es evidente en ambos mensajes: en (5) se utilizan palabras poco concretas propias de este contexto, como "y todo" y "cuando te pongas"; y en (6), el autor del mensaje utiliza un juego de palabras en "Ppodrido" para hacer referencia al PP. Sobre todo, en (5) las características propias del registro son más evidentes: cercanía, inmediatez y falta de información contextual.

Otro de los verbos con presencia en el español de la zona analizada es el de ves por ve (imperativo de $i r$ ). Si bien es cierto que tanto el $D D D$ como el $D P D$ desaconsejan el empleo de esta forma en español por considerarse vulgar, en tierras catalanas es frecuente su uso por influjo del catalán, donde se utiliza vés en el modo imperativo de anar (equivalente de ir en español):

(7) “Ves tirando tú para casa, iya me quedo yo refrescándome por aquí!” (Barcelona, $12 / 11 / 2015)$.

(8) “Ves a comprar lotería” (Mataró, 10/06/2017).

Aunque sería necesario corroborar los datos encontrados con estudios de frecuencia, los ejemplos hallados en el corpus son abundantes, lo que podría llevarnos a confirmar la extensión en el uso de este calco estructural. Otros autores, como Klee y Lynch (2009) ya advirtieron por parte de los hablantes catalanes la preferencia en el uso de ves en detrimento de ve, lo que ellos consideran una convergencia gramatical, ya que según Seco (1986) el uso de la primera forma está presente en el habla coloquial de toda España. Si tenemos en cuenta que normativamente el imperativo acabado en $s$ es reconocido como vulgar, debemos considerarlo como un calco debido a la influencia del catalán, donde sí que aparece vés como parte de la conjugación del verbo anar. Además, Galindo Solé (2003) aporta datos cuantitativos como resultado de unas grabaciones realizadas en un contexto coloquial. La autora asegura haber encontrado un uso mayoritario de ves en las zonas catalanas con una frecuencia absoluta de 7 (ves) y 1 (ve) en el total de los casos analizados. Estos datos permiten concluir, en palabras de la autora, que "ves can be considered the habitual form in Catalonia" (2003: 22).

Ambos tuits son del tipo conversacional-fático por ir dirigidos a una persona en concreto y los dos pueden identificarse con la función dialógica por formar parte de una conversación. El 
contenido de los mensajes nos permite ubicarlos en el registro coloquial, puesto que se trata de fragmentos de una conversación en la que los interlocutores parecen tener cierta proximidad.

También se hallan usuarios que utilizan la combinación mirar de con el sentido de 'procurar'. En catalán es común escuchar esta expresión, aunque el DIEC2 (s. v. mirar) remite a procurar cuando se dispone a definir esta construcción, lo que nos hace pensar que probablemente se prefiera el uso de este segundo verbo. La decisión, por parte de la norma catalana, de remitir a procurar puede ser, en parte, porque mirar de en otros territorios puede emplearse en contextos coloquiales, según el DPD (s. v. mirar). Aun así, este mismo diccionario señala se trata de un "uso que puede deberse, en algunos casos, al influjo del catalán", como podemos comprobar en los mensajes que aparecen a continuación:

(9) “[...] Miraré de pasar a visitaros más a menudo" (Sant Andreu de la Barca, 01/04/2014)

(10) "Avisadme con tiempo para mirar de organizarme" (Badalona, 05/09/2014)

En ambos casos podría cambiarse esta estructura por procurar; sin embargo, por el contacto del español y el catalán es frecuente observar el uso del calco estructural mirar de en detrimento del anterior.

Los mensajes anteriores corresponderían al tipo de tuit conversacional-fático y estarían relacionados con la función dialógica, ya que son fragmentos de conversaciones dirigidas a otro usuario que interactúa directamente con los emisores. Una vez más, es posible observar la cercanía entre los interlocutores por el contenido de los mensajes: en (9) se habla de ir a visitar a los destinatarios más frecuentemente y en (10) planifican una salida conjunta.

Con todo, los datos aportados en los párrafos anteriores, los cuales se muestran en la Tabla 1, nos permiten corroborar la presencia de este tipo de calcos en Twitter. Además, hemos podido comprobar que dichos calcos estructurales se insertan de manera natural en el discurso sin marcas tipográficas o metalingüísticas que dejen entrever un uso consciente por parte de los usuarios.

\begin{tabular}{|c|c|c|c|}
\hline $\begin{array}{c}\text { VERBO O } \\
\text { EXPRESIÓN } \\
\text { ANALIZADA }\end{array}$ & $\begin{array}{l}\text { SIGNIFICADO } \\
\text { ADQUIRIDO DEL } \\
\text { CATALÁN }\end{array}$ & $\begin{array}{c}\text { FORMA } \\
\text { NORMATIVA EN } \\
\text { CATALÁN }\end{array}$ & $\begin{array}{c}\text { FORMA } \\
\text { NORMATIVA } \\
\text { EN ESPAÑOL }\end{array}$ \\
\hline Enchegar & $\begin{array}{l}\text { Fer que (una cosa) comenci a } \\
\text { anar, a funcionar, a rutllar }\end{array}$ & Engegar & Encender \\
\hline $\begin{array}{c}\text { Encontrar a faltar / } \\
\text { echar a faltar / hallar } \\
\text { a faltar }\end{array}$ & $\begin{array}{l}\text { Adonar-se que no és allà } \\
\text { on hauria d'ésser, sentir-ne } \\
\text { la llunyania, la pèrdua, la } \\
\text { desaparició }\end{array}$ & Trobar a faltar & $\begin{array}{l}\text { Echar de menos / } \\
\text { echar en falta }\end{array}$ \\
\hline Estar de algo & Cessar de fer quelcom & $\begin{array}{l}\text { Estar de fer alguna } \\
\text { cosa }\end{array}$ & Acabar \\
\hline Estarse de algo & Privar-se'n, no fer-la & Estar-se d'alguna cosa & Abstenerse \\
\hline Ves & Imperatiu del verb català anar & Vés & $\mathrm{Ve}$ \\
\hline Mirar de & Procurar & Mirar de & Procurar \\
\hline
\end{tabular}

Tabla 1. Calcos estructurales resultantes del contacto español-catalán en la zona de Barcelona. 
A modo de resumen, en la Tabla anterior se puede observar cómo los verbos y las expresiones que se han analizado en este epígrafe adoptan la forma propia del catalán para reemplazar, en los casos analizados, la forma canónica del español. En este sentido, podemos concluir afirmando que estos calcos estructurales, según los datos aportados en esta investigación y las contribuciones publicadas por otros autores en estudios precedentes, corresponden a lo que venimos denominando como español de Cataluña y, más concretamente, de Barcelona.

\subsection{Calcos semánticos}

Dos de los verbos más utilizados tanto en español como en catalán son abrir-cerrar / obrir-tancar, respectivamente. La influencia del catalán en esta zona ha propiciado el uso de estos verbos con complementos que en español no son habituales. En este sentido, no es extraño observar cómo algunos hablantes que residen en Cataluña utilizan estas unidades verbales en sustitución de encender y apagar. Prueba de lo expuesto son los tuits que se muestran a continuación:

(11) "Abrir la tele y que el debate esté en cada canal... Qué tortura" (Barcelona, 13/06/2016).

(12) "Me da rabia faltar a la universidad por la migraña, pero [...] es que no puedo ni abrir las luces de mi casa del dolor" (Barcelona, 22/02/2017).

(13) "Mirad si hay crisis que han cerrado el aire acondicionado en el Corte Inglés. Esto parece un horno" (Barcelona, 16/07/2011).

(14) "Aquí [...] celebrando su número 1 [...], luego han cerrado el ordenador y se han abierto unas latas de cerveza" (Barcelona, 02/08/2017).

En las obras consultadas del catalán no hay evidencias de que el uso de obrir y tancar se asocie con el significado de encender y apagar en español, lo cual es curioso si observamos su uso en Twitter. Si nos detenemos en cada uno de ellos, según el DLE (s. v. abrir), este vocablo se define en su tercera acepción como "Descorrer el pestillo o cerrojo, desechar la llave, levantar la aldaba o desencajar cualquier otra pieza o instrumento semejante con que se cierra algo"; asimismo, en catalán, esta misma palabra aparece definida en la primera acepción del DIEC2 (s. v. obrir) como "Fer accessible (allò que està tancat o clos) llevant o movent la porta, la tapa, etc., que ho tanca o clou o separant dues parts juntes". Asimismo, en la cuarta acepción de la obra catalana se añade que esta palabra también puede hacer referencia a "Llevar o moure (allò que intercepta l'entrada o la sortida)". En las tres definiciones anteriores, sobre todo en las propuestas para el catalán, se desprende el valor metafórico de 'movimiento', lo cual significa que la acción formulada por abrir algo conlleva como resultado el acceso a lo que estaba anteriormente cerrado o la circulación de aquello que estaba retenido. Como consecuencia, en catalán el uso metafórico del verbo obrir se ha trasladado, incluso, a aquellos aparatos u objetos que requieren de una acción previa para que estos se pongan en funcionamiento. Por tanto, en (11) y (12) se utiliza el verbo abrir con el significado propio de encender, debido al influjo ejercido por el empleo de estos verbos en catalán.

Lo mismo ocurre con el verbo cerrar, que en español se define como "Asegurar con cerradura, pasador, pestillo, tranca u otro instrumento, una puerta, ventana, tapa, etc., para impedir que se abra" (DLE, s. v. cerrar). En catalán, además de compartir este significado, 
también se encuentra definido en su segunda acepción como "Fer funcionar (el dispositiu mitjançant el qual es fixa la cosa que intercepta el pas) de manera que aquesta resti fixada i el pas interceptat" (DIEC2, s. v. tancar). En este sentido, volvemos a tener una segunda definición en la que aparece la idea de 'movimiento' asociada a un bloqueo para evitar la circulación y el paso, al contrario de lo que sucede con su antónimo. Quizá, este énfasis, existente sobre todo en catalán, ha desembocado en el uso extensivo de este verbo para referirse a la acción de base metafórica relacionada con la interrupción del paso de la electricidad mediante un impulso (como, por ejemplo, apretar un botón para iniciar la función de apagado de un dispositivo). Por este motivo, en (13) y (14) el uso del verbo cerrar debe interpretarse como un calco semántico de esta palabra en catalán. Si bien es cierto que la norma catalana no reconoce este uso, la Corporació Catalana de Mitjans Audiovisuals recoge como ejemplo tancar el llum de la habitació cuando explica el género masculino que adquiere la palabra llum cuando se utiliza como aparato eléctrico ${ }^{7}$. Esto nos hace pensar que, para estas dos formas verbales en catalán, la norma y el uso no van en la misma dirección, puesto que, como ya señala Szigetvári (1994: 9), los "informantes nativos la[s] reconocen como muy característica[s] del catalán".

Los 4 tuits son informativos porque comunican lo que están viviendo en ese momento, además el (11) y el (13) añaden una valoración a la información precedente, lo que también los identifica como conversacionales-fáticos. La función comunicativa en todos los casos es la discursiva, ya que no mantienen una conversación directa con una sola persona, sino que exponen una información que puede ser respondida y seguida por los demás usuarios. También es evidente que nos encontramos ante el registro coloquial: en (11), (12) y (13) los autores muestran emociones y sensaciones como "Qué tortura", "Me da rabia faltar a la universidad" y "Esto parece un horno", respectivamente, como consecuencia de la situación en la que se encuentran. En (14) es posible hallar el deíctico "Aquí" para ubicar la acción, acompañada de una imagen en la que se puede ver a dos personas con unas latas de cerveza, símbolo de que están celebrando algún éxito profesional. Tanto la imagen como el mensaje contribuyen a situar en el contexto coloquial el contenido de lo que se pretende transmitir.

Si continuamos con el análisis del corpus, es posible encontrar evidencias del verbo acostumbrar seguido de la preposición $a$ con el sentido de soler en español:

(15) "También me gusta la canción de Born... la acostumbro a tatarear cuando sale [en la radio]" (L'Hospitalet de Llobregat, 07/06/2016).

(16) "A mí ni me cae bien ni mal. No acostumbro a tener sentimientos acerca de gente que no conozco, pero sus declaraciones no son muy inteligentes" (Barcelona, 03/08/2017).

En el DLE (s. v. acostumbrar) esta palabra se define como "Hacer adquirir costumbre de algo", "Tener costumbre de algo" y "Adquirir costumbre de algo"; con lo cual, en español no se registran usos de este verbo con los significados que posee en catalán: "Davant d'infinitiu introduït per la preposició $a$ o de, fer habitualment l'acció indicada per aquell infinitiu" y "Davant d'infinitiu introduï per la preposició $a$ o de, esdevenir-se habitualment allò que indica l'infinitiu" (DIEC2, s. v. acostumar). Así pues, el verbo en catalán adquiere, según el contexto, el sentido de 'ser frecuente', uso que pertenece al

7 Consúltese en http://esadir.cat/entrades/fitxa/id/1119. 
verbo soler en español. Por tanto, en (15) y (16) los usuarios utilizan acostumbrar a con la extensión de significado que existe en catalán, pero no en español, por lo que podemos clasificar este uso como un calco semántico del catalán.

En cuanto a los tipos de tuits, el (15) es informativo y el (16) podría identificarse como conversacional-fático, puesto que evalúa las declaraciones de una persona pública y se posiciona al respecto. La función comunicativa en (15) es la dialógica porque es un mensaje dirigido a alguien en concreto; mientras que en (16) la que predomina es la discursiva por formar parte de un conjunto de mensajes acerca de un tema específico. Si tenemos en cuenta el contenido de los mensajes, podemos decir que el registro en el que se enmarcan es el coloquial. Ambos tuits expresan opiniones: el primero relacionado con los gustos musicales y el segundo dirigido a valorar el sentimiento que le produce las declaraciones de una persona que desconoce. En ambos contextos es posible deducir que existe una tendencia a la cercanía por parte de los autores, debido, probablemente, a que expresan pensamientos personales.

A diferencia de los casos anteriores, hay verbos como aburrir y aborrecer en español que solo poseen un equivalente en catalán: avorrir. El DLE (s. v. aburrir) considera que esta palabra significa "Molestar, cansar, fastidiar"; sin embargo, en su cuarta acepción se explicita que puede utilizarse como sinónimo de aborrecer aunque está marcada como en desuso. Si consultamos la definición de este último término, el $D L E$ (s. v. aborrecer) determina que significa "Tener aversión a alguien o algo" y en la tercera acepción encontramos de nuevo una referencia directa a la palabra aburrir con el significado de "molestar". Como se puede comprobar, el diccionario permite, en ocasiones, intercambiar ambas palabras; aun así, en el español de Cataluña es posible observar la presencia de aborrecer en detrimento de aburrir por la influencia del catalán, ya que en este idioma solo existe un vocablo, avorrir, que aglutina ambas definiciones y cuyos significados son "Tenir aversió (a algú o a alguna cosa)", "Agafar aversió (a algú o a alguna cosa)", "Causar (a algú) tedi” y "Sentir tedi” (DIEC2, s. v. avorrir). Para lo que en catalán es aburrir en su primera acepción, en español se utiliza aborrecer y viceversa, lo que ayuda a entender por qué algunos hablantes catalanes suelen utilizar aburrir en detrimento de la anterior para expresar el sentimiento de rechazo hacia algo o alguien. En Twitter podemos confirmar lo expuesto:

(17) "Yo lo tengo aburrido, prefiero escuchar otros como el tuyo" (Sant Just Desvern, 03/08/2013).

(18) "Cuando algo empieza a ser conocido, lo aburro" (Barcelona, 02/08/2017).

Asimismo, como respuesta al mensaje (17), la destinataria (de procedencia colombiana) entiende que el remitente catalán utiliza aburrir con el sentido de 'algo soso, cansado' y no con el significado de aborrecer. Ante esta interpretación, contesta lo siguiente: “¿Aburrido? Aburrido el mío [...]" (Bogotá, 03/08/2013). En los dos ejemplos se hace un uso de aburrir propio de aborrecer, puesto que el significado que prevalece en estos contextos es el de 'tener aversión' y no el de 'molestar'. Por todo esto, es posible deducir que los usuarios en cuestión han empleado este término con el significado de la palabra catalana, por lo que podemos clasificarlo como un calco semántico. Sin embargo, también es posible hablar de convergencia, ya que no se produce una estructura agramatical, como sería el caso de una interferencia. La influencia del catalán en esta zona propicia el uso preferente de aburrir por aborrecer. 
Por lo que se refiere a los tipos de tuits, el (17) podría clasificarse como conversacionalfático y el (18) como informativo. En esta misma línea, el primero se relaciona con la función dialógica, puesto que forma parte de una conversación entre dos personas (una muestra de ello es el "tuyo" que utiliza el usuario para dirigirse a la destinataria); y el segundo desempeñaría una función discursiva por ser un mensaje que permite la interacción con otros usuarios mediante la publicación de comentarios como respuesta a este tuit. Una vez más, el registro coloquial está presente en estos mensajes. En ambas publicaciones es posible advertir cómo los usuarios expresan preferencias o valoraciones personales acerca de un tema en concreto. En (17) es más fácil de reconocer este contexto, puesto que de este mensaje y de los siguientes se desprende cierto afecto por la destinataria de los tuits, lo cual permite confirmar la proximidad entre los interlocutores. En (18) no es tan evidente esta cercanía, pero, como se acaba de mencionar, al tratarse de una descripción personal, se acerca más a lo coloquial.

Otro caso de convergencia a partir de un calco semántico lo hallamos en el verbo agradar que, en ocasiones, y según los datos recogidos, puede utilizarse como sinónimo de gustar por influencia catalana. Hablamos de convergencia porque el DLE (s. v. agradar) lo define como "Complacer, contentar, gustar", por lo que deducimos que, dependiendo del contexto, el intercambio de estos dos verbos es posible. Aun así, como señala Szigetvári (1994) en su investigación, el uso de agradar por gustar en español es restringido, lo que nos permite asegurar que en la zona analizada se produce un influjo del verbo agradar en catalán, definido como "Ésser del grat d'algú, fer-li una impressió grata, satisfer-ne el gust" (DIEC2, s. v. agradar). Por todo ello se deduce que el contacto entre estas dos lenguas puede conllevar entre algunos hablantes el uso preferente de agradar con el sentido de gustar, tal y como hemos podido comprobar en los mensajes de Twitter que se presentan a continuación:

(19) "Siempre que le oigo en los medios, me agrada [n] mucho sus intervenciones. Es muy didáctico y divertido, explica con claridad. Saludos" (Barcelona, 07/06/2012).

(20) "No soporto a la gente que critica a sus padres y, en cambio, me agrada mucho la gente como ahora tú, que los tiene siempre presentes" (Molins de Rei, 26/10/2012) ${ }^{8}$.

Ambos tuits son conversacionales-fáticos, puesto que expresan una valoración y forman parte de una conversación mantenida con otra persona. Además, ambos pueden reconocerse como dialógicos, en cuanto a la función comunicativa se refiere. Si bien es cierto que en el primer caso no detectamos índices de coloquialidad, sino más bien se tiende a mostrar cierta distancia con el destinatario del mensaje por el trato de usted y la despedida formal "Saludos", el segundo mantiene un tono de proximidad al opinar acerca de la gente que critica a los padres.

Un caso semejante lo encontramos con los verbos pegar y enganchar, cuyo equivalente único en catalán es enganxar. En español, enganchar se utiliza, entre otros significados, para hacer referencia a "Prender algo con un gancho o colgarlo de él" (DLE, s. v. enganchar). En catalán, además de poseer este sentido, también se define en la primera de sus segundas acepciones como "Unir, fer adherir, amb cola o qualsevol matèria aglutinant viscosa"

8 La estructura como ahora es una interferencia del catalán com ara, utilizada en este contexto para anunciar un ejemplo. 
(DIEC2, s. v. enganxar). Este significado no lo encontramos en español puesto que para este fin existe la palabra pegar: "Unir una cosa con otra mediante alguna sustancia" (DLE, s. v. pegar). En Twitter es posible encontrar varios ejemplos de lo que acabamos de comentar:

(21) “[...] muy cívico lo vuestro, enganchar carteles en la entrada de un local” (Barcelona, 09/09/2014).

(22) "Se refiere a lo de enganchar purpurina. Cuando tienes cuatro años, esas cosas cuestan..." (Barcelona, 26/07/2017).

Ante estos datos, llegamos a la conclusión de que se trata de un calco semántico, puesto que el verbo español enganchar adquiere el significado de 'unir' por el contacto con el catalán.

Los tuits anteriores podrían clasificarse como conversacionales-fáticos (21), por dirigirse directamente a un grupo de personas en concreto, e informativo (22), por intentar aclarar una situación que parece no haberse entendido anteriormente. Además, el primero estaría relacionado con la función discursiva, ya que forma parte de un tema en concreto en el que la gente escribe sobre él; y el segundo con la dialógica por el hecho de ser un mensaje destinado a otro usuario en particular. Los dos tuits poseen un carácter irónico, concretamente en "muy cívico lo vuestro" y "Cuando tienes cuatro años, esas cosas cuestan". Precisamente, este tono burlón acerca el contenido del mensaje al registro coloquial.

Dos de los verbos más frecuentes tanto en español como en catalán son dar y hacer, puesto que pueden formar numerosas expresiones; de ahí que se denominen verbos de apoyo (Alonso Ramos, 2004). De todos modos, en catalán el uso de hacer es más habitual, por lo que debido a la influencia entre las dos lenguas que aquí nos conciernen no es de extrañar que en los territorios catalanes se utilice este verbo "en combinaciones que parecen no ser tan habituales fuera de las zonas en las que el catalán convive con el español” (Freixas Alás, 2016: 227). Algunas de las expresiones que hemos hallado en Twitter con estos verbos son las siguientes ${ }^{9}$ :

(23) "Qué fácil es dar la culpa a la pobre infermera. Siempre perdemos la clase media baja" (Santa Perpètua de la Mogoda, 09/10/2014) ${ }^{10}$.

(24) “ ¡Me alegro! Hay variedad de rutinas en el canal, por si quieres dar un vistazo. ¡Un beso!” (Barcelona, 04/03/2015).

(25) "A mí me hace gracia ir a Sagrera [...]" (Santa Coloma de Gramenet, 30/12/2013).

(26) “Roncero, haces mala cara. ¿Qué te pasa, chato?” (Barcelona, 04/03/2015).

(27) "Si ya lo dicen que tanto deporte no es bueno... Tocará hacer un poco de bondad para recuperar bien [...]" (El Masnou, 11/08/2015).

(28) "Hacer la siesta con otra persona es lo mejor del mundo" (Barcelona, 30/07/2017).

(29) "Me encanta cuando en agosto el transporte público se reduce a la mitad. Parece que según ellos todo el mundo hace vacaciones" (Barcelona, 01/08/2017).

(30) “¡Jefe! Hoy hago años, ¿será posible que me prestes un segundo y me mandes un beso y un abrazo apreta[d]o?” (Barcelona, 01/08/2017).

9 Es necesario resaltar que, debido al gran número de usos relacionados con el verbo hacer, hemos optado por exponer seis casos para evidenciar la proliferación de combinaciones existentes influenciadas por el catalán. Para el verbo dar hemos seguido la misma metodología que con los demás verbos estudiados en esta investigación, por lo que solo mostramos dos de los ejemplos encontrados.

10 En este caso el usuario emplea infermera por enfermera debido a una interferencia con el catalán. 
Los dos primeros casos, el (23) y el (24), son traducciones literales del uso de estas expresiones en catalán. En español, la culpa se echa, no se da; lo mismo que ocurre con un vistazo, que debe ir precedido también por echar. Este tipo de preferencias responden a cuestiones de fijación formal y semántica, puesto que cada lengua tiene a su disposición una serie de estructuras, llamadas unidades fraseológicas, que funcionan como un bloque y suelen presentar predilecciones a la hora de combinarse con unos u otros elementos. En español, echar "Junto con algunos nombres, tiene la significación de los verbos que se forman de ellos o la de otros equivalentes. Echar maldiciones, maldecir; echar suertes, sortear; echar un cigarro, fumarlo; echar un sueño, dormir; echar la siesta, sestear" (DLE, s. v. echar). En este sentido, echar la culpa y echar un vistazo estarían relacionados con los verbos culpar y examinar, respectivamente. En catalán, sí que encontramos estas estructuras con el equivalente formal de dar: donar la culpa y donar una ullada, ya que en este idioma dicho verbo puede significar 'atribución', como ocurre con echar en español. Por este motivo, el uso de dar en las colocaciones anteriormente presentadas son el resultado de un calco semántico del catalán.

En cuanto a los ejemplos con el verbo hacer, las posibilidades combinatorias de este verbo en catalán son inmensas, además de tratarse de un verbo soporte como hemos comentado anteriormente, lo que facilita la transferencia de rasgos propios de esta lengua al español. En el caso (25), el usuario emplea hacer gracia en vez de apetecer, debido al influjo de la estructura fer gràcia en catalán para referirse a 'llamar la atención o atraer algo'. Del mismo modo, en (26) se utiliza este verbo para designar el estado anímico de una persona, cuyo malestar es evidente por el aspecto de la cara. En español se construye con el verbo tener, por lo que puede corroborarse la influencia del catalán en el ejemplo extraído. En (27) se observa un uso típico del español de Cataluña con el verbo hacer, cuyo equivalente en español es portarse bien. Este es uno de los casos más evidentes de influencia lingüística, puesto que en español no existe ninguna combinación parecida con el sustantivo bondad. Por lo que se refiere al ejemplo (28), volvemos a estar ante la sustitución de echar por otro verbo más típico en catalán, como es hacer. En español utilizamos echar la siesta, mientras que en catalán la estructura se ha fijado con el verbo de apoyo indicado. En cuanto al enunciado (29), también existen diferencias entre el español y el catalán a la hora de referirse al tiempo de descanso por trabajo o estudios. Una vez más observamos cómo el catalán influye directamente sobre la construcción en español, que se combinaría con el verbo estar. Finalmente, en (30) el usuario utiliza el verbo propio de la expresión catalana en detrimento de cumplir. Este es uno de los casos que más puede detectarse en una zona no catalanohablante, ya que la diferencia entre ambas expresiones es más evidente.

En suma, todos pueden identificarse como calcos semánticos, por el hecho de transferir una parte del significado del verbo hacer en catalán a los verbos correspondientes en la otra lengua, excepto hacer bondad, que se trata de un calco estructural y semántico, por no existir una combinación semejante en español con esta forma y sentido. El DDD (s. v. hacer) también reconoce algunas de estas expresiones como propias del "castellano hablado por catalanes".

En los 8 tuits mostrados anteriormente podemos encontrar variedad en cuanto al tipo de mensaje y a las funciones comunicativas. El (23) y el (29) podrían clasificarse como conversacionales-fáticos, ya que valoran la situación que describen; los mensajes (24), (25) y (28) son informativos; el (27) además de informativo se identifica con el tipo de tuit denominado de reconocimiento, puesto que utiliza una frase popular como autoridad para manifestar su opinión acerca de practicar deporte en exceso; y los mensajes (26) y (30) se 
clasificarían como búsqueda de información, puesto que formulan preguntas con la finalidad de que el destinatario responda. Por lo que se refiere a las funciones, los tuits (23), (27), (28) y (29) pertenecerían a lo discursivo porque forman parte de una cadena de mensajes acerca de un mismo tema; mientras que los ejemplos (24), (25), (26) y (30) se relacionarían con la función dialógica por estar dirigidos a una persona en concreto, lo que facilita la continuidad de la conversación entre los dos usuarios. Los rasgos coloquiales son fáciles de identificar en la mayoría de casos. Una vez más, las opiniones, las emociones y los sentimientos son los protagonistas en el contenido de cada uno de estos tuits. También encontramos una fórmula irónica, como en (29), cuando el usuario escribe: "Me encanta cuando en agosto el transporte público se reduce a la mitad", justamente para expresar su descontento con la situación. La presencia de algunos vocativos, como "chato" (26) o "¡Jefe!" (30) indican cierta proximidad con el destinatario del mensaje, ya que estas fórmulas se utilizan en contextos coloquiales. Finalmente, otra muestra de cercanía es la fórmula de despedida en (24) y la demanda afectuosa en (30): “ Un beso!” y "me mandes un beso y un abrazo apreta[d] o?”. En este último ejemplo podemos observar, además, la omisión de la $d$ intervocálica en "apretao", lo que demuestra la tendencia a economizar la lengua, como ocurre en el contexto oral cuando se adopta el registro coloquial.

Otro de los verbos más extendidos en las zonas catalanas a la hora de referirse a la finalización de la jornada laboral es plegar. En español este verbo no está en absoluto relacionado con dicha denotación, sino que solo se utiliza para hacer referencia a la acción de "Hacer pliegues en una cosa" (DLE, s. v. plegar); por lo contrario, sí que lo encontramos con este sentido en catalán: "Interrompre la feina per a reprendre-la al dia següent, després d'un repòs, etc.” (DIEC2, s. v. plegar), lo que ha facilitado su transferencia al español de Cataluña:

(31) "Yo plego tarde del partido y dudo que esté antes de [las] 10:30" (Cornellà de Llobregat, 09/08/2012).

(32) "Ver como todo el mundo plega a las $17 \mathrm{~h}$. y tú plegas a las 21 h., jtiene que ser un nuevo pecado capital!" (Barcelona, 07/05/2014).

Por tanto, podemos clasificar esta palabra como calco semántico, puesto que en español no existe ningún elemento léxico con esta forma con el significado de 'acabar o interrumpir la jornada laboral'. Aun así, es necesario resaltar que el verbo plegar en español con el sentido de 'doblar' es irregular, mientras que el otro mantiene su forma en toda la conjugación, lo que nos permite advertir que también se trata parcialmente de un calco estructural ${ }^{11}$.

El primer tuit es del tipo conversacional-fático y el segundo es informativo. La función comunicativa que se encuentra en el mensaje (31) es la dialógica, puesto que forma parte de una conversación con otra persona. En el ejemplo (32) la función es la discursiva, ya que se trata de un comentario general que va destinado a cualquiera que lea su perfil y quiera responder el mensaje. Aunque los rasgos coloquiales no son tan evidentes en estos dos tuits, del primero se intuye cierta cercanía con el destinatario.

Después de haber realizado el análisis de los calcos semánticos documentados en Twitter, los cuales se recogen en la Tabla 2, podemos observar cómo algunos verbos del español amplían su significado con una acepción propia de los vocablos catalanes, cuyo uso parece estar limitado a las zonas donde conviven las dos lenguas que aquí nos conciernen.

11 Para más información acerca de las formas diptongadas de plegar, véase el § 4.10d de la NGLE (2009). 


\begin{tabular}{|c|c|c|c|}
\hline $\begin{array}{c}\text { VERBO O } \\
\text { EXPRESIÓN } \\
\text { ANALIZADA }\end{array}$ & $\begin{array}{l}\text { SIGNIFICADO } \\
\text { ADQUIRIDO DEL } \\
\text { CATALÁN } \\
\end{array}$ & $\begin{array}{c}\text { FORMA } \\
\text { NORMATIVA } \\
\text { EN CATALÁN } \\
\end{array}$ & $\begin{array}{l}\text { FORMA } \\
\text { NORMATIVA EN } \\
\text { ESPAÑOL } \\
\end{array}$ \\
\hline Abrir & $\begin{array}{l}\text { Llevar o moure (allò que } \\
\text { intercepta l'entrada o la } \\
\text { sortida) }\end{array}$ & Obrir & Encender \\
\hline Cerrar & $\begin{array}{l}\text { Fer funcionar (el dispositiu } \\
\text { mitjançant el qual es fixa la } \\
\text { cosa que intercepta el pas) } \\
\text { de manera que aquesta resti } \\
\text { fixada i el pas interceptat }\end{array}$ & Tancar & Apagar \\
\hline Acostumbrar a & $\begin{array}{l}\text { Davant d'infinitiu introduït } \\
\text { per la preposició } a \text { o de, } \\
\text { esdevenir-se habitualment allò } \\
\text { que indica l'infinitiu }\end{array}$ & Acostumar a & Soler \\
\hline Aburrir & Sentir tedi & Avorrir & Aborrecer \\
\hline Agradar & $\begin{array}{c}\text { Ésser del grat d'algú, fer-li } \\
\text { una impressió grata, satisfer- } \\
\text { ne el gust }\end{array}$ & Agradar & Gustar \\
\hline Enganchar & $\begin{array}{l}\text { Unir, fer adherir, amb cola o } \\
\text { qualsevol matèria aglutinant } \\
\text { viscosa }\end{array}$ & Enganxar & Pegar \\
\hline Dar la culpa & $\begin{array}{l}\text { Atribuir-li d'haver-ne estat } \\
\text { causa }\end{array}$ & Donar la culpa & Echar la culpa \\
\hline Dar un vistazo & Mirada ràpida, cop d'ull & Donar una ullada & Echar un vistazo \\
\hline Hacer gracia & $\begin{array}{c}\text { Algú o alguna cosa, plaure, } \\
\text { especialment per la seva } \\
\text { gràcia o gràcies }\end{array}$ & Fer gràcia & Apetecer \\
\hline Hacer mala cara & $\begin{array}{l}\text { Mostrar displicència envers } \\
\text { alguna cosa }\end{array}$ & Fer mala cara & Tener mala cara \\
\hline Hacer bondad & $\begin{array}{c}\text { Comportar-se bé, especialment } \\
\text { un infant }\end{array}$ & Fer bondat & Portarse bien \\
\hline Hacer la siesta & $\begin{array}{l}\text { Dormida que es fa després de } \\
\text { dinar }\end{array}$ & Fer la migdiada & Echar la siesta \\
\hline Hacer vacaciones & $\begin{array}{l}\text { Temps de repòs concedit a un } \\
\text { funcionari o a un treballador }\end{array}$ & Fer vacances & Estar de vacaciones \\
\hline Hacer años & $\begin{array}{c}\text { Ésser aquest dia l'aniversari } \\
\text { de la seva naixença }\end{array}$ & Fer anys & Cumplir años \\
\hline Plegar & $\begin{array}{l}\text { Interrompre la feina per a } \\
\text { reprendre-la al dia següent, } \\
\text { després d'un repòs, etc }\end{array}$ & Plegar & $\begin{array}{c}\text { Finalizar la jornada } \\
\text { laboral }\end{array}$ \\
\hline
\end{tabular}

Tabla 2. Calcos semánticos resultantes del contacto español-catalán en la zona de Barcelona. 
A partir de lo expuesto en este apartado, creemos conveniente señalar que la aparición de estos verbos y expresiones depende de distintos factores. Como señala Sinner (2004: 91),

siempre cabe la posibilidad de que estas informaciones circulen más entre ciertas capas de la sociedad, en determinados grupos sociales, etarios, etc., dependiendo de las variables sociolingüísticas como la formación intelectual, el grado de conocimiento del catalán y del castellano, del uso y conocimiento de las respectivas normas, etc.

En este sentido, los datos que hemos encontrado en Twitter han ayudado a verificar que el contacto de lenguas puede darse en todos los contextos comunicativos, independientemente del canal de transmisión, siendo el oral el más proclive a producir este tipo de fenómenos. Con todo, hemos podido comprobar que las formas estudiadas aparecen en el español hablado por los catalanes que residen en la provincia de Barcelona.

\section{CONCLUSIONES}

Después de realizar esta investigación podemos concluir que las redes sociales, como Twitter, son una fuente de información muy útil para conocer los usos lingüísticos de una comunidad determinada. La geolocalización de los mensajes extraídos ha permitido conocer de primera mano el lugar en el que residen las personas que han publicado los tuits, por lo que esto facilita reducir la búsqueda a una zona determinada, como Barcelona. Según ya se ha comentado a lo largo del estudio, las evidencias de las que disponemos son muestras reales de lengua, aunque no pueden asociarse estrictamente a un contexto oral o escrito. Aun así, como se ha podido comprobar en cada uno de los mensajes analizados, los rasgos que poseen estos mensajes permiten situarlos bajo un registro conversacional y, normalmente, también cercanos al coloquial. Esto nos lleva a pensar que, en un contexto distendido, en el que la presión normativa no está presente, los usuarios de esta red utilizan un lenguaje cercano, incluso con personas que probablemente no han visto nunca, lo que favorece la aparición de ciertos fenómenos relacionados con el contacto de lenguas. En la mayoría de los ejemplos mostrados se han podido detectar algunos índices de coloquialidad que permiten confirmar la importancia de este registro en cuanto a la aparición de calcos en español y catalán. Cabría investigar, en futuras publicaciones, si estos fenómenos también se registran en contextos más formales, lo que ayudaría a completar la hipótesis de que, en las situaciones de inmediatez comunicativa, los contactos lingüísticos son más frecuentes.

También es interesante resaltar que la mayoría de tuits que constituyen nuestro corpus de estudio son informativos y/o conversacionales-fáticos, lo que estaría en consonancia con el registro coloquial, puesto que los primeros exponen una situación, normalmente cotidiana, que los usuarios están viviendo en tiempo real; y los segundos son fragmentos de conversaciones entre dos personas, donde suele prevalecer la proximidad entre los interlocutores. Asimismo, las principales funciones comunicativas que desempeñan los mensajes analizados son la dialógica y la discursiva, también vinculadas a un contexto donde la inmediatez y la cercanía son las protagonistas.

A partir de los datos analizados hemos podido observar que la mayoría de fenómenos están relacionados con los calcos estructurales y semánticos (véase las respectivas síntesis en las Tablas 1 y 2). Si bien es cierto que, en ocasiones, es difícil establecer la frontera entre 
un calco y una interferencia en sentido estricto, en esta investigación se ha concebido de manera amplia el concepto de catalanismo, por lo que todos los calcos estudiados formarían parte de lo definido como préstamo. Sin embargo, somos conscientes de lo complejo que supone considerar si todos los casos tratados pueden identificarse como parte del español de Cataluña (concretamente de Barcelona) o si deben considerarse como desvíos de la norma hasta que la Academia decida integrarlos en sus obras. De todos modos, sí que podemos corroborar que los datos analizados nos han ayudado a demostrar la presencia de verbos y expresiones en Twitter como resultado del contacto entre el español y el catalán. En líneas generales, el verbo hacer es el más productivo en cuanto a la creación de nuevas estructuras influenciadas por el catalán. También resulta interesante destacar que los calcos semánticos parecen estar más aceptados por los hablantes catalanes ya que la frecuencia de aparición en Twitter es mayor que la de los calcos estructurales. Es posible que esto sea así debido a que la integración de nuevos vocablos mediante préstamos suele ser un proceso más lento (e incluso menos aceptado socialmente) que la adición de nuevos significados a palabras o estructuras ya existentes en la lengua influenciada, por no conllevar la creación de un nuevo elemento en la lengua de destino. Además, como hemos comentado durante el análisis, la reacción de los destinatarios al escuchar ciertas palabras o estructuras propias, en este caso, del español de Cataluña, y que no conocen (la mayoría considerarían que son incorrectas) puede conllevar una agresión en la imagen del emisor, por lo que, en futuras investigaciones, sería interesante tener en cuenta cómo influyen las actitudes lingüísticas en la producción y aceptación de estos fenómenos. Un buen punto de partida podrían ser los trabajos de Moreno Fernández (2012) y Caravedo (2014), cuyas aportaciones ayudan a justificar, desde la sociolingüística cognitiva, lo que acabamos de exponer.

En suma, la metodología de análisis empleada ha permitido aportar una nueva perspectiva de estudio al ámbito de la variación lingüística, ya que aún son escasos los datos sobre el contacto de lenguas (sobre todo entre el español y el catalán) en las redes sociales. Si tenemos en cuenta que estamos frente a un discurso emergente donde la interacción entre el texto, la imagen y la inmediatez comunicativa juegan un papel significativo, el análisis de mensajes publicados en las redes sociales puede ayudarnos, como se ha pretendido demostrar en esta investigación, a corroborar los estudios precedentes y a aportar nuevos datos sobre el contacto entre estas dos lenguas en Twitter tanto desde un punto de vista lingüístico como discursivo a través del análisis del contexto, el registro y las funciones comunicativas que encontramos en el contenido de los mensajes. Somos conscientes de que aún queda un largo camino por recorrer, por lo que pretendemos seguir contribuyendo en sucesivos trabajos a establecer las características propias del español de Cataluña.

\section{Referencias bibliográficas}

Alonso Ramos, M. (2004): Las construcciones con verbo de apoyo. Madrid: Visor Libros.

Androutsopoulos, J. (2008), "Potentials and limitations of discourse-centred online ethnography", Language@Internet, 5. Disponible en línea: http://www.languageatinternet.org/articles/2008/1610 (última consulta en septiembre de 2017).

Blas Arroyo, J. L. (1991): "Problemas teóricos en el estudio de la interferencia lingüística", Revista de la Sociedad Española de Lingüística, 21, 2, pp. 265-289.

Blas Arroyo, J. L. (2004): "El español actual en las comunidades del ámbito lingüístico catalán”. En Rafael Cano Aguilar (coord.): Historia de la lengua española. Barcelona: Ariel, pp. 1065-1086. 
Caravedo, R. (2014): Percepción y variación lingüistica. Enfoque sociocognitivo. Madrid/Frankfurt am Main, Iberoamericana/Vervuert.

Clyne, M. G. (1967): Transference and triggering: observations on the language assimilation of postwar German-speaking migrants in Australia. The Hague: Martinus Nijhoff.

$D D D=$ Seco, M. (1998): Diccionario de dudas y dificultades de la lengua española, 10. edición. Madrid: Espasa Calpe.

DIEC2 = Institut d'Estudis Catalans (2007): Diccionari de la llengua catalana, 2. ${ }^{\text {a }}$ edición. Consulta en línea: http://dlc.iec.cat/ (última consulta en agosto de 2017).

$D L E=$ Real Academia Española y Asociación de Academias de la Lengua Española (2014): Diccionario de la lengua española, $23^{\mathrm{a}}$ edición. Consulta en línea: http://dle.rae.es/ (última consulta en agosto de 2017).

$D P D=$ Real Academia Española (2005): Diccionario panhispánico de dudas. Consulta en línea: http:// www.rae.es/recursos/diccionarios/dpd (última consulta en agosto de 2017).

Freixas Alás, M. (2016): "Combinaciones léxicas con el verbo hacer en el español del Cataluña". En D. Poch Olivé (ed.): El español en contacto con las otras lenguas peninsulares. Frankfurt am Main: Iberoamericana Vervuert, pp. 225-263.

Galindo Solé, M. (2003): "Language contact phenomenon in Catalonia: The influence of Catalan in spoken Castilian". Selected Followings of the First Workshop on Spanish Sociolinguistics, Lotfi Sayahi (ed.). Somerville: MA, Cascadilla Followings Project, pp. 18-29.

García Rodríguez, J. (2014): El tratamiento de los coloquialismos en los diccionarios didácticos: análisis lexicográfico, lexicológico y pragmático. Trabajo Final de Máster. Universitat Autònoma de Barcelona. Disponible en línea: http://ddd.uab.cat/record/130408 (última consulta en septiembre de 2017).

García Sanz, A. (2011): La interferencia lingüística en los medios de comunicación escritos: La Vanguardia y algunos catalanismos léxicos. Trabajo Final de Máster. Universitat Autònoma de Barcelona. Disponible en línea: https://ddd.uab.cat/pub/trerecpro/2011/hdl_2072_203103/CATALANISMOS_ EN_LOS_MCE_LA_INTERFERENCIA.pdf (última consulta en septiembre de 2017).

Gómez Capuz, J. (1998): El préstamo lingüístico. Conceptos, problemas y métodos. Cuadernos de Filología, Anejo XXIX. Valencia: Universidad de Valencia.

Haugen, E. I. (1953): The Norwegian language in America: A study in bilingual behaviour. Philadelphia: University of Pennsylvania Press.

Ivković, D. y Lotherington, H. (2009), "Multilingualism in cyberspace: conceptualising the virtual linguistic landscape", International Journal of Multilingualism, 6/1, pp. 17-36.

Klee, C. A. y Lynch, A. (2009): El español en contacto con otras lenguas. Washington, D.C.: Georgetown University Press.

Koch, P. y Oesterreicher, W. (2007): Lengua hablada en la Romania: español, francés, italiano. Madrid: Gredos.

Lara, T. (2011): "Twitter y sus funciones comunicativas", Revista Lenguaje y Textos, 34, Sociedad Española de Didáctica de la Lengua y la Literatura. Disponible en línea: http://tiscar. com/2012/03/11/twitter-y-sus-funciones-comunicativas (última consulta en septiembre del 2017).

Mackey, W. F. (1970): Interference, integration and the synchronic fallacy. International Center of Research on Bilingualism. Quebec: Laval University.

Mancera Rueda, A. y Pano Alamán, A. (2013): El español coloquial en las redes sociales. Madrid: Arco/Libros.

Mancera Rueda, A y Pano Alamán, A. (2014a): “La conversación en Twitter: las unidades discursivas y el uso de marcadores interactivos en los intercambios con parlamentarios españoles en esta red social", Estudios de Lingüística del Español, 35, pp. 243-277.

Mancera Rueda, A. y Pano Alamán, A. (2014b): "Las redes sociales como corpus de estudio para el Análisis del discurso mediado por ordenador." Humanidades Digitales: desafios, logros y perspectivas de futuro. Janus, Anexo 1, pp. 305-315. 
Mocanu, D.; Baronchelli, A.; Perra, N.; Gonçalves, B.; Zhang, Q.; y Vespignani (2013): “The Twitter of Babel: Mapping World Languages through Microblogging Platforms", PLoS ONE, 8, 4. Disponible en línea: http://journals.plos.org/plosone/article/file?id=10.1371/journal.pone.0061981\&type=printable (última consulta en julio de 2017).

Moreno Cabrera, J. C. (2016): Multilingüismo y lenguas en contacto. Madrid: Editorial Síntesis.

Moreno Fernández, F. (2012): Sociolingüistica cognitiva. Proposiciones, escolios y debates. Madrid/ Frankfurt am Main, Iberoamericana/Vervuert.

Moreno Sandoval, A. y Moreno Fernández, F. (2017): Búsqueda de anglicismos en el español estadounidense a través de Twitter. Informe del observatorio de la lengua española y las culturas hispánicas en los Estados Unidos. Instituto de ingeniería del conocimiento. Disponible en línea: http://www.iic.uam.es/wp-content/uploads/2017/04/Anglicismos-Twitter.pdf (última consulta en julio de 2017).

$N G L E=$ Real Academia Española (2009): Nueva gramática de la lengua española. Consulta en línea: http://aplica.rae.es/grweb/cgi-bin/buscar.cgi (última consulta en agosto de 2017).

Payrató, Ll. (1985): La interferència lingüistica: comentaris $i$ exemples català-castellà. Barcelona: Curial.

Pérez, F. J. (2010): “Las nuevas redes sociales, ¿moda o revolución?”, Nuestro Tiempo, pp. 52-61. Disponible en línea: http://dadun.unav.edu/handle/10171/11993 (última consulta en agosto de 2017).

Poch Olivé, D. (ed.) (2016): El español en contacto con las otras lenguas peninsulares. Frankfurt am Main: Iberoamericana Vervuert.

Polo García, J. D. (2009): Twitter... para quien no usa Twitter. Ed. Bubok.

Prat Sabater, M. (2003): Préstamos del catalán en el léxico español. Bellaterra: Universitat Autònoma de Barcelona, Departamento de Filología Española. Disponible en línea: http:/www.tdx.cat/ handle/10803/4864 (última consulta en julio de 2017).

Sánchez Sánchez, M. (2012): “Las redes sociales, ¿nuevos soportes para el estudio de la lengua?”, Cum corde et in nova grammatica, pp. 750-777.

SIE = Fundación Telefónica (2016): La Sociedad de la Información en España, 2016. Madrid: Fundación Telefónica / Barcelona: Ariel. Disponible en línea: https://www.fundaciontelefonica.com/arte_cultura/ publicaciones-listado/pagina-item-publicaciones/itempubli/558/ (última consulta en julio de 2017).

Sinner, C. (2000): "Frecuencia de perífrasis verbales como índice de variación lingüística", Revista de Lingüística Teórica y Aplicada, 38. Concepción de Chile, pp. 149-159.

Sinner, C. (2004): El castellano de Cataluña. Estudio empírico de aspectos léxicos, morfosintácticos, pragmáticos y metalingüisticos. Tübingen: Max Niemeyer Verlag.

Sinner, C. y A. Wesch, (eds.) (2008): El castellano en tierras de habla catalana, Madrid-Frankfurt am Main: Iberoamericana-Vervuert.

Szigetvári, Mónika (1994): Catalanismos en el español actual (tesis de licenciatura). Budapest: Eötvös Loránd Tudományegyetem. Disponible en línea: http://carstensinner.de/castellano/szigetvari.pdf (última consulta en julio de 2017).

Thurlow, C. y K. Mroczek (2011): Digital discourse: Language in the new media. Nueva York: Oxford University Press.

Weinreich, U. (1979 [1953]): Languages in contact. Findings and problems. Paris-New York: Mouton Publishers-The Hague. 